\title{
SMS Based Wireless Home Appliance Control System (HACS) for Automating Appliances and Security
}

\section{Malik Sikandar Hayat Khiyal, Aihab Khan, and Erum Shehzadi Software Engineering Dept., Fatima Jinnah Women University, Rawalpindi, Pakistan}

\author{
m.sikandarhayat@yahoo.com; aihabkhan@yahoo.com; \\ engrerum@yahoo.com
}

\begin{abstract}
This paper mainly focuses on the controlling of home appliances remotely and providing security when the user is away from the place. The system is SMS based and uses wireless technology to revolutionize the standards of living. This system provides ideal solution to the problems faced by home owners in daily life. The system is wireless therefore more adaptable and cost-effective. The HACS system provides security against intrusion as well as automates various home appliances using SMS. The system uses GSM technology thus providing ubiquitous access to the system for security and automated appliance control.
\end{abstract}

Keywords: Short Message Service (SMS), Global System for Mobile communication (GSM), Radio Frequency (RF), AT Commands, ubiquitous access and Automation.

\section{Introduction}

The aim of the paper is to investigate a cost effective solution that will provide controlling of home appliances remotely and will also enable home security against intrusion in the absence of home owner.

The motivation is to facilitate the users to automate their homes having ubiquitous access. The system provides availability due to development of a low cost system. The home appliances control system with an affordable cost was thought to be built that should be mobile providing remote access to the appliances and allowing home security.

Home security has been a major issue where crime is increasing and everybody wants to take proper measures to prevent intrusion. In addition there was a need to automate home so that user can take advantage of the technological advancement in such a way that a person getting off the office does not get melted with the hot climate. Therefore this paper proposes a system that allows user to be control home appliances ubiquitously and also provide security on detection of

Material published as part of this publication, either on-line or in print, is copy righted by the Informing Science Institute. Permission to make digital or paper copy of part or all of these works for personal or classroom use is granted without fee provided that the copies are not made or distributed for profit or commercial advantage AND that copies 1) bear this notice in full and 2) give the full citation on the first page. It is permissible to abstract these works so long as cred it is given. To copy in all other cases or to republish or to post on a server or to redistribute to lists requires specific permission and payment of a fee. Contact Publisher@InformingScience.org to request redistribution permission. intrusion via SMS using GSM technology.

The next section will explain the related work; section 3 explains the proposed system, methodology and algorithm. Section 4 discusses the framework, working, characteristics, strengths and constraints of the system. Section 5 explains the results and section 6 is conclusions and the future work. 


\section{Related Work}

Delgado, Picking, and Grout (2006) consider the problems with the implementation of home automation systems. Furthermore the possible solutions are devised through various network technologies. Several issues affecting home automation systems such as lack of robustness, compatibility issue and acceptability among the old and disabled people are discussed.

Ciubotaru-Petrescu, Chiciudean, Cioarga, and Stanescu (2006) present a design and implementation of SMS based control for monitoring systems. The paper has three modules involving sensing unit for monitoring the complex applications. A processing unit that is microcontroller and a communication module that uses GPRS modem or cell phone via serial port RS-232. The SMS is used for status reporting such as power failure.

In their paper, Conte and Scaradozzi (2003) view home automation systems as multiple agent systems (MAS). In the paper home automation system has been proposed that includes home appliances and devices that are controlled and maintained for home management. The major task is to improve performance.

In their paper, Alkar and Buhur (2005) propose an Internet Based Wireless Home Automation System for Multifunctional Devices. This paper proposes a low cost and flexible web-based solution but this system has some limitations such as the range and power failure.

Murthy (2008) explores primary health-care management for the rural population. A solution proposes the use of the mobile web-technologies providing the PHC services to the rural population. The system involves the use of SMS and cell phone technology for information management, transactional exchange and personal communication.

Jawarkar, Ahmed, Ladhake, and Thakare (2008) propose remote monitoring through mobile phone involving the use of spoken commands. The spoken commands are generated and sent in the form of text SMS to the control system and then the microcontroller on the basis of SMS takes a decision of a particular task.

Potamitis, Georgila, Fakotakis, and Kokkinakis, G. (2003) suggest the use of speech to interact remotely with the home appliances to perform a particular action on behalf of the user. The approach is inclined for people with disability to perform real-life operations at home by directing appliances through speech. Voice separation strategy is selected to take appropriate decision by speech recognition.

\section{Preliminaries}

\section{Home Appliance Control System (HACS)}

Home appliance control system is based on GSM network technology for transmission of SMS from sender to receiver. SMS sending and receiving is used for ubiquitous access of appliances and allow ing breach control at home.

The system proposes two sub-systems. Appliance control subsystem enables the user to control home appliances remotely whereas the security alert subsystem provides the remote security monitoring. The system is capable enough to instruct user via SMS from a specific cell number to change the condition of the home appliance according to the user's needs and requirements. The second aspect is that of security alert which is achieved in a way that on the detection of intrusion the system allows automatic generation of SMS thus alerting the user against security risk.

HACS system consists of the following components (shown in Figure 1):- 
PC: This unit contains the software components such as the HACS System through which the appliances are controlled and home security is monitored.

GSM Modem: It is a hardware component that allows the capability to send and receive SMS to and from the system. The communication with the system takes place via RS232 serial port. Cell phone can be attached at the place of GSM hardware but it limits the hardware functionality such as sending or receiving of SMS.

Mobile Device: Cellular phone containing SIM card has a specific number through which communication takes place. The device communicates with the GSM Modem via radio frequency. Mobile user transmits SMS using GSM technology.

\section{Framework Overview}

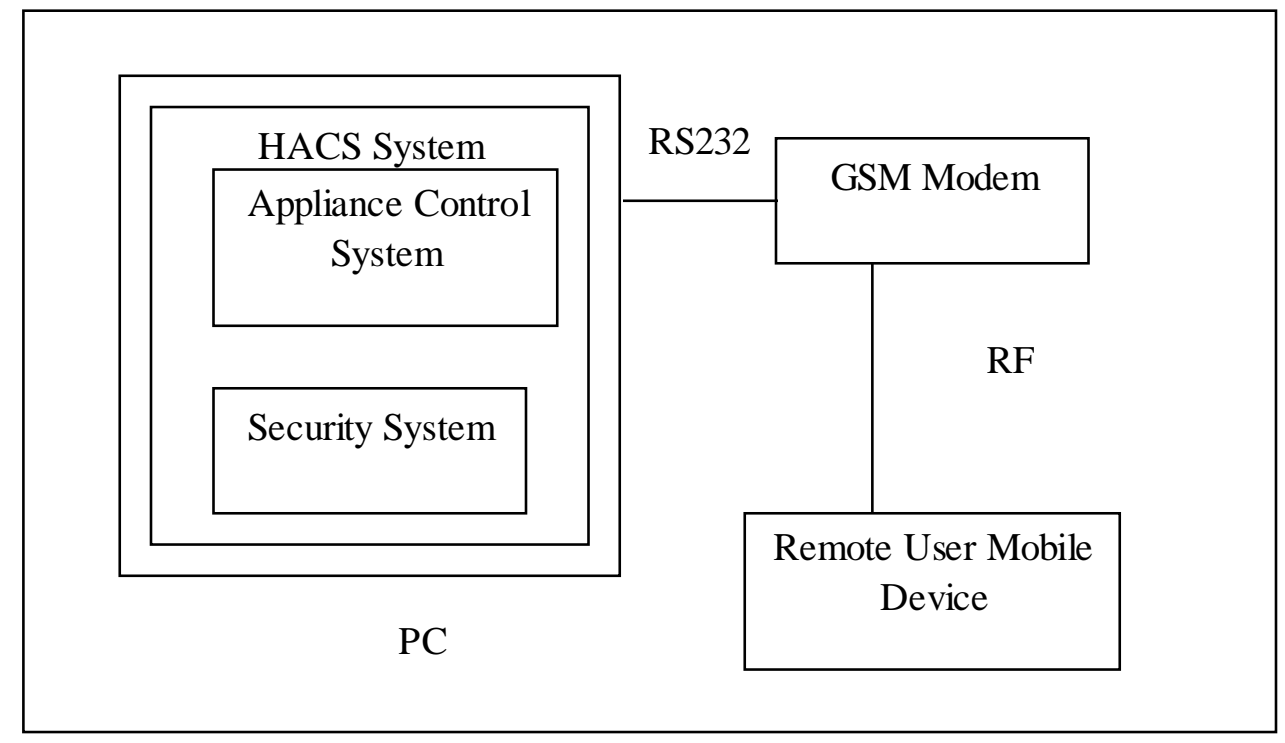

Figure 1: Model of HACS

\section{Working}

The working of HACS model (shown in Figure 1) is explained:-

PC: PC being the main module has HACS system installed on it. The two subsystems; one being appliances control is responsible for ubiquitous access of appliances and the second subsystem being security alert is responsible for security intrusion detection. Both subsystems work on GSM technology for transmission of instructions from sender to receiver.

GSM Modem: GSM modem is a plug and play device and is attached to the PC which then communicates with the PC via RS232 port. GSM modem is a bridge responsible for enabling/disabling of SMS capability.

Cell Phone: Mobile device communicates with the GSM Modem via radio waves. The mode of communication is wire less and mechanism works on the GSM technology. Cell phone has a SIM card and a GSM subscription. This cell phone number is conf igured on the system. User transmits instructions via SMS and the system takes action against those instructions.

\section{Methodology}

The methodology followed in the HACS is given as:- 
- GSM hardware tests are run in order to check the hardware support. The system will call GSM modem and it will get activated.

- After activation the Modem will check for hardware support. If the hardware is miss ing or some other hardware problem there will be error, resulting in communication failure and the application will be terminated.

- If hardware responds then the serial port will be opened for communication and GSM hardware will allow transmission of SMS.

- The system will then connect and after connection establishment the system will be able to detect intrusion and will alert user about the breach and similarly the system will update status of appliances by receiving SMS from the pre-defined cell number.

- SMS will be silently ignored if cell number is unauthorized.

\section{Pseudo code}

The pseudo code for HACS is given as:-

begin

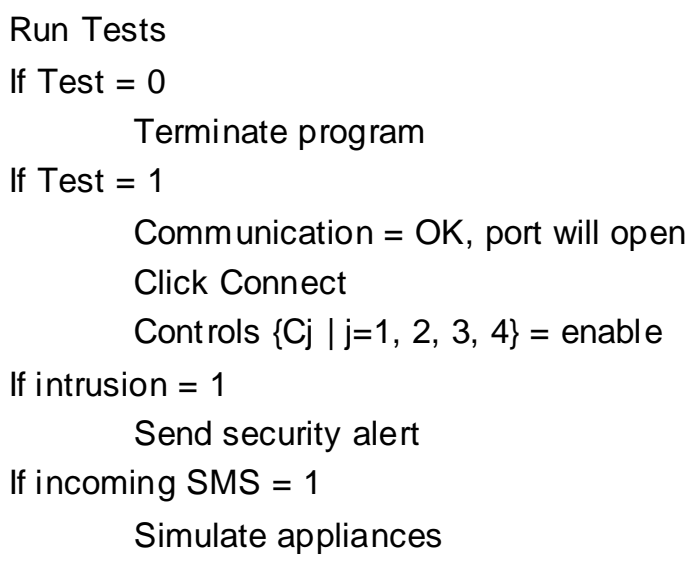

end

\section{Characteristics of HACS}

The proposed system characteristics involve remote controlling of appliances, intrusion detection, system security and auto-conf iguration such that system automatically adjusts the system settings on running hardware support check. The system has useful features such as displaying of battery level, charging status and signal strength of the mobile thus making system reliable.

\section{Strengths of HACS}

HACS system has many advantages such as remote controlling of home appliances, availability and ease of users. The user can get alerts anywhere through the GSM technology thus making the system location independent. The system contains low cost components easily available which cuts down the overall system cost.

Moreover system alerts user about breach via SMS providing home security also it allows secure access due to pre-configured number. The ease of deployment is due to wire less mode of communication. GSM technology provides the benefit that the system is accessible in remote areas as well. The system reliability increases due to the useful features such as battery level checking, charging status and signal strength indicating the system about threats. The system integration is 
simple and is also scalable and extensible. The auto-configuration capability allows the system auto enabling/disabling of certain features.

\section{Constraints of HACS}

The system functionality is based on GSM technology so the technological constraints must be kept in mind. The system is vulnerable to power failure but this disruption can be avoided by attaching the voltage source thus allowing users to avail the great advantage of this system.

\section{Results}

The results of the HACS system:-

Figure 2 shows various GSM hardware tests that will be run to check the hardware support.

The system then opens the serial port for communication with the GSM modem. On successful port opening the system communicates with the GSM Modem but if fails system does not communicate.

The system checks support for battery level, signal strength and GSM modem SMS sending and receiving capability. If these tests succeed the system gives response of 'Ok', if not then 'ERROR' is returned.

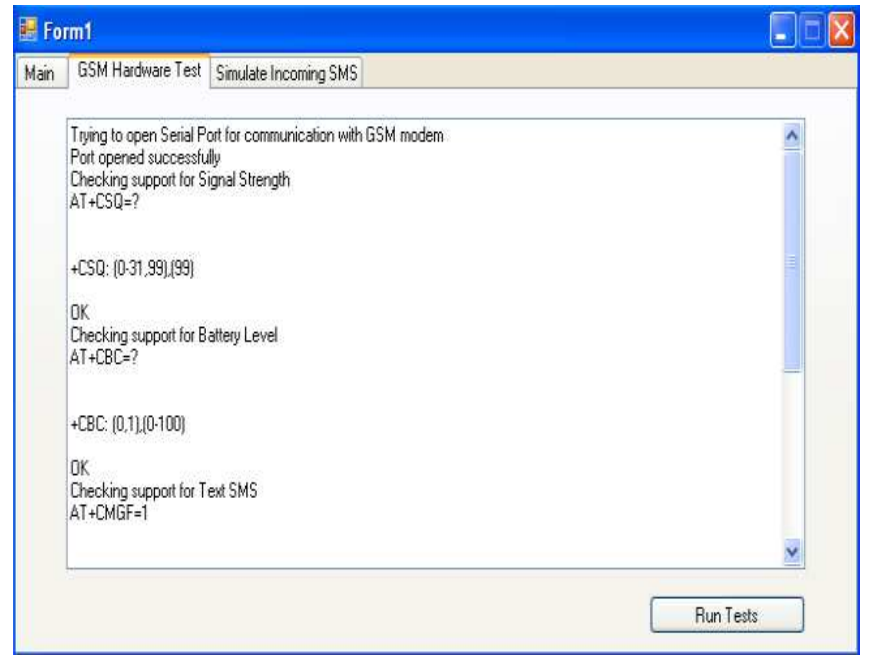

Figure 2: GSM Hardware Test

Figure 3 shows that a particular home appliance is simulated on the reception of SMS sent by the remote user.

The remote user sent SMS from a pre-configured cell number on the HACS system to turn on the sound alarm and the system performed the respective function by simulating the alarm to green color as directed by the user. 


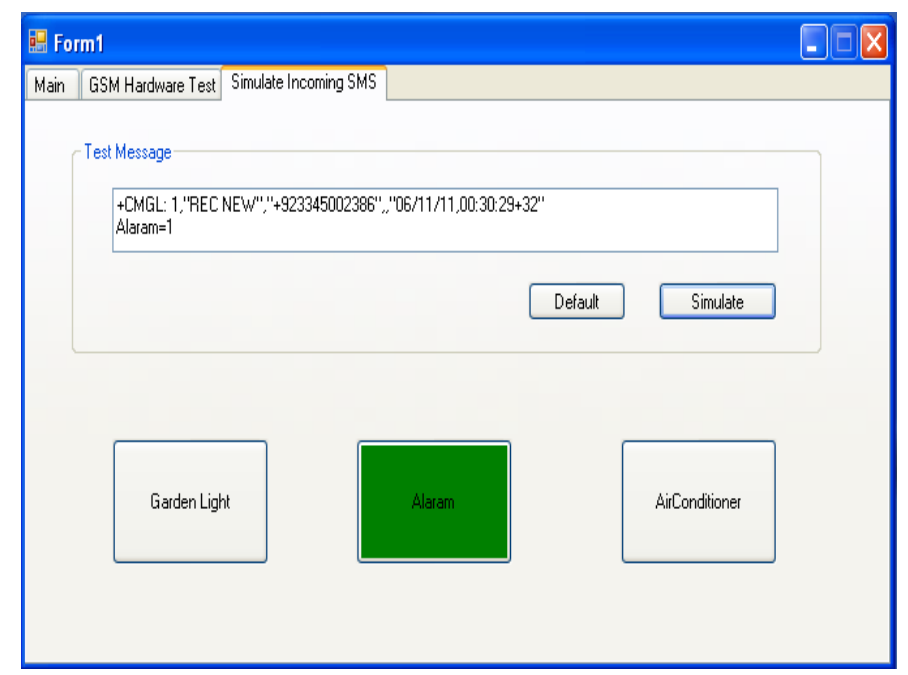

Figure 3: Simulation of Home Appliance

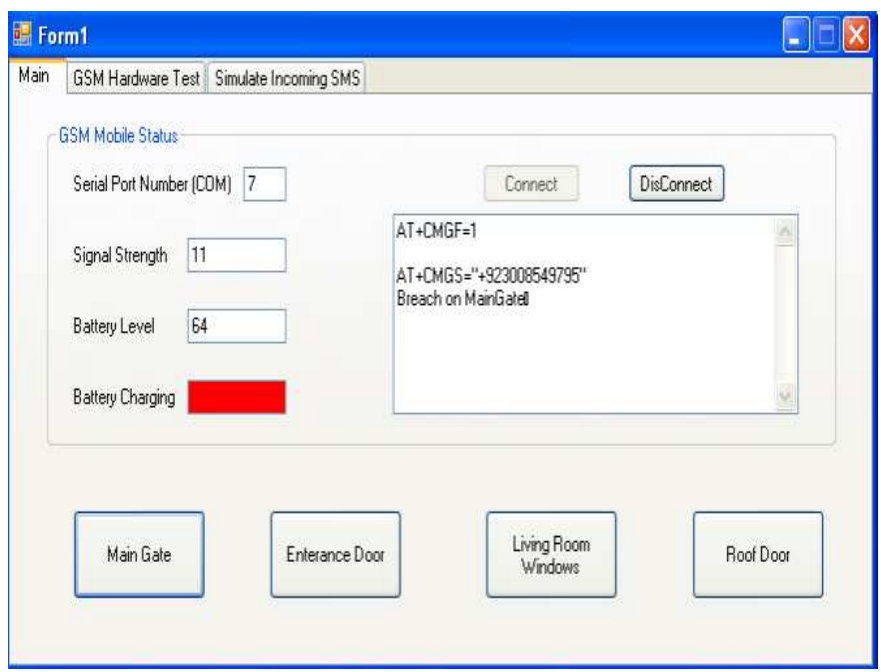

Figure 4: SMS ale rt on Intrusion De tection

Figure 4 shows the result when the event of intrusion was triggered then the system automatically generated SMS to inform the user about the security risk.

The system is constantly monitoring the battery level, charging status and signal strength. In Figure 4 is illustrating that the communication between system and GSM hardware device is taking place via COM port 7.

The tabulated results are presented in Tables 1 and 2 .

\section{Table 1: Appliance Control Sub-system}

a. Results of Appliance Control Subsystem:

\begin{tabular}{|c|c|c|}
\hline APPLIANCE & $\begin{array}{c}\text { SMS INTRUSION SENT } \\
\text { BY USER }\end{array}$ & SYSTEM RESPONSE \\
\hline Air Conditioner & Air Conditioner $=1$ & AC button simulated to green \\
\hline Alarm & Alarm $=0$ & Alarm button simulated to red \\
\hline Light & Light $=1$ & Light button simulated to green \\
\hline
\end{tabular}


Table 2: Security Alert Sub-system

\section{b. Results of Security Alert Subsystem:}

\begin{tabular}{|c|c|c|}
\hline APPLIANCE & SYSTEM ACTION & ALERT SMS RECEIVED B Y USER \\
\hline Main Gate & $\begin{array}{l}\text { Intrusion detected on Main Gate, } \\
\text { SMS generated to user }\end{array}$ & SMS received "Breach on the main gate" \\
\hline Entrance Door & $\begin{array}{l}\text { Intrusion detected on Entrance } \\
\text { Door, SMS generated to user }\end{array}$ & SMS received "Breach on the Entrance Door" \\
\hline $\begin{array}{l}\text { Living Room } \\
\text { Windows }\end{array}$ & $\begin{array}{c}\text { Intrusion detected on Living } \\
\text { Room Windows, SMS generated } \\
\text { to user }\end{array}$ & $\begin{array}{c}\text { SMS received "Breach on the Living Room } \\
\text { Windows" }\end{array}$ \\
\hline Roof Door & $\begin{array}{l}\text { Intrusion detected on Roof Door, } \\
\text { SMS generated to user }\end{array}$ & SMS received "Breach on the Roof Door" \\
\hline
\end{tabular}

Achieved analytical results :-

- System allowed the provision of security such that system took no action against the instructions received from unauthorized number. The required task was performed only when the pre-configured number instructed the system.

- System sent breach alert when the intrusion was detected.

- Remote Controlling capability of the system allowed user to switch on/off through simulating the appliance as directed by the incoming SMS.

- The system automatically performed tests and checked support for available features and SMS sending and receiving capability and configured system accordingly.

\section{Conclusion and Future Work}

In the paper low cost, secure, ubiquitous ly accessible, auto-configurable, remotely controlled solution for automation of homes has been introduced. The approach discussed in the paper is novel and has achieved the target to control home appliances remotely using the SMS-based system satisfying user needs and requirements.

GSM technology capable solution has proved to be controlled remotely, provide home security and is cost-effective as compared to the previously existing systems. Hence we can conclude that the required goals and objectives of HACS have been achieved.

The basic level of home appliance control and remote monitoring has been implemented. The system is extensible and more levels can be further developed using automatic motion/glass breaking detectors so the solution can be integrated with these and other detection systems. In case of remote monitoring other appliances can also be monitored such that if the level of temperature rises above certain level then it should generate SMS or sensors can also be applied that can detect gas, smoke or fire in case of emergency the system will automatically generate SMS.

In future the system will be small box combining the PC and GSM modem. This hardware can be imported from Taiwan and Singapore. The hardware will be self contained and cannot be prone to electric failure. This appliance will have its own encapsulated UPS and charging system. 


\section{References}

Alkar, A.Z., \& Buhur, U. (2005). An Internet Based Wireless Home Automation System for Multifunctional Devices. IEEE Consumer Electronics, 51(4), 1169-1174. Retrieved from http://www.thaieei.com/embedded/pdf/Automation/20022.pdf

Ciubotaru-Petrescu, B., Chiciudean, D., Cioarga, R., \& Stanescu, D. (2006). Wireless Solutions for Tele metry in Civil Equipment and Infrastructure Monitoring. 3rd Romanian-Hungarian Joint Symposium on Applied Computational Intelligence (SACI) May 25-26, 2006. Retrieved from http://www.bmf.hu/conferences/saci2006/Ciubotaru.pdf

Conte, G., \& Scaradozzi, D. (2003). Viewing home automation systems as multiple agents systems. RoboCUP2003, Padova, Italy. Retrieved fro $\mathrm{m}$ http://www.robosiri.it/ROBOCUP_2003/ROBOCUPSITOSIRI/artic les/pdf/Conte.pdf

Delgado, A. R., Picking, R., \& Grout, V. (2006) Re mote-controlled home auto mation systems with different network technologies. Proceedings of the 6th International Network Conference (INC 2006), University of Ply mouth, 11-14 Ju ly 2006, pp. 357-366. Retrieved from http://www.newi.ac.uk/groutv/papers/p5.pdf

Jawarkar, N. P., Ahmed, V., Ladhake, S. A. \& Thakare, R. D. (2008). Micro-controller based Remote Monitoring using Mobile through Spoken Commands. Journal Of Net works, 3(2), 58-63. Retrieved from $\mathrm{http}: / /$ www.acade mypublisher.co m/jnw/vol03/no02/jn w03025863.pdf

Murthy, M. V. R. (2008). Mobile based primary health care system for rural India. W3C workshop on Role of Mobile Technologies in Fostering Social Development, Jun 2008

Potamitis, I., Georg ila, K., Fakotakis, N., \& Kokkinakis, G. (2003). An integrated system for smart-home control of appliances based on remote speech interaction. EUROSPEECH 2003, 8th European Conference on Speech Communication and Technology, pp. 2197-2200, Geneva, Switzerland, Sept. 1-4, 2003. Retrieved fro $\mathrm{m}$ http://www.wcl.ee.upatras.gr/ai/papers/potamit is 14.pdf

\section{Biographies}

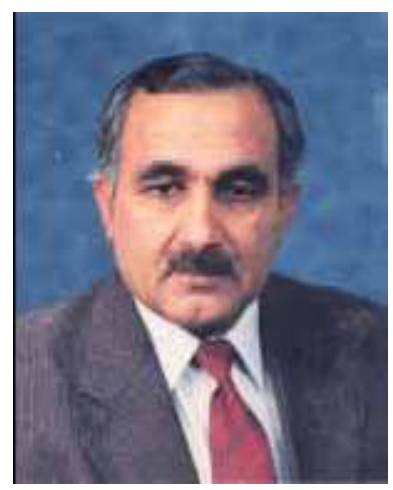

Dr. Malik Sikandar Hayat Khiyal born at Khushab, Pakistan. He is Chairperson Department of Computer Sciences and Software Engineering at Fatima Jinnah Women University, Pakistan. He received his M.Sc degree from Quaid-e-Azam University, Is lamabad. He got first position in the faculty of Natural Science of the University. He was awarded the merit scholarship for Ph.D. He received his Ph.D. degree from UMIST, Manchester, U.K. He developed software of underground flow and advanced fluid dynamic techniques. His areas of interest are Numerical Analysis, Mode ling and Simulation, Discrete structure, Data structure, Analysis of Algorithm, Theory of Automata and Theory of Computation. He has more than fifty research publication published in National and International Journals and Conference proceedings. He can be contacted at m.sikandarhayat@yahoo.com, Fatima Jinnah Women University, Rawalpindi Pakistan.

Mr. Aihab Khan works in Department of Computer Sciences Fatima Jinnah Women University, Pakistan. His research interests are in the field of Data mining, Data Warehousing as well as Information Security. He can be contacted at aihabkhan@ yahoo.com, Fatima Jinnah Women University, Rawalpindi Pakistan.

Ms. Erum Shehzadi is a software engineer graduate from Department of Software Engineering, Fatima Jinnah Women University, Pakistan. She can be contacted at engr_erum@yahoo.com. 